\title{
Be(com)ing an excellent student: a qualitative study with engineering undergraduates
}

Sílvia Monteiro $^{\mathrm{a} *}$, Leandro S. Almeida ${ }^{\mathrm{b}}$, Rosa M. Vasconcelos ${ }^{\mathrm{c}}$ and

José Fernando A. Cruz ${ }^{\mathrm{a}}$

${ }^{a}$ School of Psychology, University of Minho, Braga, Portugal; ${ }^{b}$ Institute of Education, University of Minho, Braga, Portugal; ${ }^{c}$ School of Engineering, University of Minho, Guimarães, Portugal

This study explores the factors affecting the development of academic excellence on a group of 33 high-achieving engineering students. Participants were interviewed individually to explore several personal and contextual aspects of their past and current academic pathways. The results obtained reflect three main contributions to the conceptualization and understanding of excellence in academic contexts: the need to adopt a multidimensional and dynamic view about the concept of excellence; the existence of a variety of possible pathways and environmental conditions to achieve excellence; and the understanding of excellence as a process undergoing continuous development, which thrives within the family context and school environment, and that seems to be continuously nurtured by individuals in interaction with their contexts.

Keywords: excellence; higher education; developmental process; engineering students

\section{Introduction}

Several theories have been developed concerning the concepts of talent, expertise, or excellence, fuelling the discussion about what determines excellence. While some researchers defended genetics as an explanation of exceptional abilities in young children, others presented evidence indicating an absence of early precursors of high skill levels (Howe, Davidson, \& Sloboda, 1998). One of the most cited talent development theories, the Differentiated Model of Giftedness and Talent (Gagné, 2000, 2004), describes a process of transformation of natural abilities or gifts into outstanding, systematically developed skills which defined expertise or talent in a particular occupational field. In other words, one cannot become talented if lacking "a gift." However, such a natural ability needs to be transformed into talent through intrapersonal (such as personal traits or self-management processes) and environmental catalysts (such as socio-demographic factors, psychological influences, or facilities and programs designed to develop special talents), which interact in different ways from one person to the next with no single causal component. Here, the learning process is presented as a product of the interaction between intrapersonal and environmental catalysts, which contribute toward the manifestation of talent. As an example, Gagné (2004) refers to the talented and highly motivated students who

*Corresponding author. Email: silviamonteiro@ie.uminho.pt 
study more to get high(er) grades; as a consequence, such students will receive help from their parents to improve their personal work habits, or even, to have access to advanced learning or training opportunities, helping to improve their performance. This may be a bi-directional relationship (parents reacting to the students' behaviors or the students reacting to parents' input), and can occur in a positive or negative sense. Finally, the role of chance and opportunities is also considered to have an influence in this process, as does the quality of the parenting received.

Expert performance approaches on the other hand (Ericsson, Nandagopal, \& Roring, 2009; Ericsson, Roring, \& Nandagopal, 2007) minimized the importance of innate abilities. Such approaches stated that difference between experts and nonexperts is a result of extensive experience (at least 10 years) acquired through intensive practice, and not dictated by basic cognitive processes. Such deliberate practice activities are usually preceded by early engagement, in which individuals develop motivation and enjoyment in a specific domain. Following early practice, individuals are able to engage in intensive and regular practice, which may not necessarily be enjoyable. Deliberate practice represents an activity beyond simple mechanization or task automation; rather, it implies an intentional focus in performance improvement, achieved through structured activities. According to this perspective, "prodigies" are not the product of a natural gift; "prodigies" were exposed to exceptional environmental conditions, which allowed their early engagement in deliberate practice activities. As a consequence, expert performance approaches stated that almost anyone can achieve superior performance, as long as they benefit from the necessary environmental conditions and deliberately practice towards continuous progression in their performance. Individual learning differences result from differentiated prior knowledge, skills structure, and learning strategies.

In spite of theoretical arguments - one in favor of an innate gift, the second stressing the role of experience and practice - there is a general lack of empirical evidence to sufficiently support the arguments that are currently provided by each side of the debate concerning excellence. Models which focused on gifts and talent, rely on the imperative argument of the existence of a set of dispositional abilities prior to the development of talent (e.g. Gagné, 2004; Renzulli, 1986), are criticized for failing to demonstrate enough evidence indicating that eminent adults had been children with innate abilities (Ericsson et al., 2007). In turn, expert performance approaches (Ericsson et al., 2007, 2009; Ericsson \& Smith, 1991) have difficulty to empirically supporting the idea that people with high levels of performance do not have innate predisposition for specific skills (referring only to very specific characteristics, such as height or weight, as genetically inherited attributes), particularly when the excellence starts in childhood. The critics argue that the empirical evidence only demonstrates a correlation between the amount of practice and the acquisition of performance, and not a causal relation, which can also suggest that both variables are nothing more than a reflection of another factor, such as parental encouragement, for example (Sternberg, 1998).

Despite the limitations of each approach, as well as the discrepancies between different models of excellence, recent attempts have been made to combine the several research paradigms in order to optimize our knowledge about giftedness or talent (Heller, 2004; Ziegler \& Heller, 2000). A common aspect of the different theoretical models concerns the importance of contextual factors for the development and sustenance of excellence in academic contexts. The importance of contextual factors has, in fact, been thoroughly discussed in the literature in the field of gifted 
education. A recent paper by Albert Ziegler and Shane Phillipson, entitled "Towards a systemic theory of gifted education" (Ziegler \& Phillipson, 2012), has started the debate about the need for change in the fields of giftedness and gifted education, with a focus on the interactions of cognitive and non-cognitive factors, and on the understanding of the system that leads to exceptionality.

In giftedness and talent models, the role of the environment is presented as a determinant catalyst for the expression of innate abilities on performance (Gagné, 2004; Renzulli, 1986). On the other hand, in the expert performance approaches, contextual factors are presented as being important conditions in earlier stages of development, leading to the engagement in deliberate practice activities and to the stimulation of motivation toward a specific domain of expertise (Ericsson et al., 2009). The influence of contextual factors on the development of talent is also a prevalent aspect in the field of Mathematics. Longitudinal studies, such as the Study of Mathematically Precocious Youth (e.g. Lubinski \& Benbow, 2006; Lubinski, Webb, Morelock, \& Benbow, 2001), have demonstrated that an appropriate response to students' interest and abilities increases the probability of them following a career related to mathematics two decades later. In their mid-30s, these students also reported high job satisfaction, satisfaction with the direction their careers took, and perceived success in their careers (Lubinski, Benbow, Webb, \& Bleske-Rechek, 2006). A recent study conducted in Korea, a country known for its high achievements in the Third International Mathematics and Science Study, and the Progra for International Students Assessment (PISA) also address the influence of family and societal experiences on the career choices of gifted girls. In this country, there are large gender differences in the gifted population and girls are underrepresented in mathematics and sciences. These differences seem to derive from social influences associated with psychological factors such as self-confidence and interests (Lee \& Sriraman, 2012). Therefore, it seems that all the environmental conditions are important and play a fundamental role, not only for the development of students' interests and practice initiation on specific domains, but also for their choices and future career pathway.

Even though contextual factors are generally acknowledged as impacting the development of talent, one aspect that seems to be less clear in either approach is the kind of balance established between personal factors (such as personality characteristics, and with the ways how students engage in tasks, as well as practice and motivation) and contextual factors (environmental positive or negative influences and/or experiences on individual development and practice) in the explanation of excellence in achievement contexts.

This perspective of context dependency is not exclusive of gifted education. The social-cognitive view of learning has presented students' individual and contextual characteristics, inherent to students' development, as two sets of variables which do not operate as isolated variables in a vacuum. Instead, the learning process is described as a set of reciprocal interactions between behavioral, environmental, and personal variables (Bandura, 1986). Therefore, this perspective includes a combination of cognitive, motivational, and emotional processes that are believed to operate interactively. An application on the social-cognitive approach in academic contexts concerns the use of self-regulation skills. These skills have recently been studied within expert performance approaches, in order to offer a better understanding of the development of expertise in academic contexts (Nandagopal \& Ericsson, 2012; Zimmerman, 2006). Here, self-regulatory competence involves three core elements: 
covert self-regulating of personal processes, behavioral performance, and environmental setting (Bandura, 1986). Successful learners monitor and regulate these triadic elements in a strategically coordinated and adaptive manner (Zimmerman, 2006). Self-regulatory skills are differentiated by prior and subsequent events; this has driven the attention to the importance of empirical studies to explain the authentic contexts of learning, rather than exclusively focusing research on aptitude scales that are designed to accumulate self-regulatory responses over time (Zimmerman, 2008). As Butler (2002) argued, the adoption of self-regulated approaches to learning depends on social contexts in which individuals exist and perform. Then, selfregulated learning seems to emerge from more than just individual knowledge and skill, now involving social aspects that include interactions with peers and teachers. Therefore, research on self-regulatory learning processes should take into accounts not only enumeration or quantification of study strategies, but also their meaning in the context in which they occur.

From the literature review, we hypothesize that excellent performance is the result of an interaction between person and environment, with mutual influences throughout individuals' development. We aim to analyze the role of previous educational experiences and learning environments in the explanation of academic excellence. It is conceivable that academic excellence is the result of continuous experiences, and not a definitive achievement, namely in childhood and adolescence.

Our results will be analyzed in order to distinguish contextual from personal factors in high achievement. In the discussion section, we will explore the interplay of these factors with the excellence pathways of a group of engineering students. Traditionally in Portugal, engineering courses have been amongst the least pursued courses by applicants to higher education. According to the last report from the Portuguese Higher Education Politics Research Centre (CIPES, 2008), approximately half of the students who access engineering courses are not taking their desired or "first-choice" course, (or taking a first choice, it can represent a convenience choice because of the lower access rates in engineering courses in Portugal (Vasconcelos, Almeida, \& Monteiro, 2006)). This problem reflects particularly on academic performance, considering that, in Portugal, engineering course rates are among the lowest when compared to all subject areas (GPEARI, 2008), which has led institutions to keep particularly focused on students' academic failure and dropout. Therefore, engineering students who outperform their peers may represent a key variable to understanding academic excellence in this context: not only personal characteristics of high achievers, but also contextual variables that promote. Therefore, it is our goal to explore personal and contextual factors impacting the development of these students who stand out academically.

\section{Method \\ Participants}

The participants of this study, presented in Table 1, were 33 engineering students from 3 Portuguese public universities, with an average course grade higher than 16 (ranging from 0 to 20). This average course grade clearly stands out among general engineering students, who achieve an average course grade below 13. The number of students in this high-achieving cohort normally represents one to two percent of 
Table 1. Participants.

\begin{tabular}{|c|c|c|c|c|c|c|c|c|c|}
\hline \multicolumn{2}{|c|}{ Course year } & \multicolumn{2}{|c|}{ Gender } & \multicolumn{2}{|c|}{ Age } & \multicolumn{2}{|c|}{$\begin{array}{c}\text { Average } \\
\text { course grade } \\
\text { (participants) }\end{array}$} & \multicolumn{2}{|c|}{$\begin{array}{l}\text { Average course } \\
\text { grade } \\
\text { (engineering } \\
\text { students) }\end{array}$} \\
\hline $3 \mathrm{rd}$ & 4th & $\bar{M}$ & $\bar{F}$ & $\overline{\text { Mean }}$ & $\overline{\mathrm{SD}}$ & Mean & $\overline{\mathrm{SD}}$ & Mean & SD \\
\hline 21 & 12 & 27 & 6 & 20.85 & 1.2 & 17.41 & 0.81 & 12.76 & 1.28 \\
\hline
\end{tabular}

the total number of students in the third, fourth, and fifth years of engineering courses. Hence, these students were collected based on a specific purpose rather than randomly (Teddlie \& Tashakkori, 2009), representing selected informants who could provide relevant information to the phenomenon being investigated. Thirty-eight students from three Portuguese public universities were invited to participate in our study. From these, 33 students agreed to collaborate (about $87 \%$ of the total invited participants). Participants who agreed to participate signed an informed consent form, describing the aims of the study and ensuring anonymity and confidentiality of the collected information.

\section{Procedure}

This study follows a qualitative approach, seeing that semi-structured interviews were conducted and then analyzed. As argued by Yin (1994), an optimal time to use qualitative methods is when it is not possible to separate a phenomenon from its context. Taking into account the intention to adopt an integrative and systematic overview of excellence, such approach seems to be the most appropriate methodological choice for the aim of this study.

A protocol guide with specific topics and questions to address was also developed. The chosen topics of the semi-structured guide were adapted to the academic context from a previous interview guide developed by Araújo, Cruz, and Almeida (2011), and emerged from a theoretical review.

In a second stage, the validity and clarity of the interview guide was evaluated by psychological supervisors, as suggested by Whittemore, Chase, and Mandle (2001). The final version of the interview guide was composed of eight major topics, which formed the bases of open-ended questions about students' past and current academic pathways: (i) previous educational pathway (e.g. "tell me about your academic pathway up until college"); (ii) current performance (e.g. "could you please describe a typical workweek?"); (iii) task involvement - practice (e.g. "imagine that you have an important work to present; how do you prepare it?"); (iv) personal characteristics (e.g. "what do you think are the ingredients for your success?"); (v) significant others (e.g. "which people had a significant impact on your life?"); (vi) interpersonal relationships (e.g. "how would you describe your friends?"); (vii) perceptions within academic community (e.g. "what is it like to be an excellent student taking an engineering course?"); (viii) projects and professional aspirations (e.g. “what are your main goals or professional aspirations?"). Besides these main topics, participants were asked about other aspects they considered important for their high achievement, in order to get a better understanding of possible variables 
involved in excellence, either personal or contextual, which could have been unaccounted for so far.

Concerning the training of the interviewer, she had previous experience in qualitative methodologies and consulted other experienced qualitative researchers. In addition, five pilot interviews were conducted in order to develop some previous practice with the specific interview guide and to refine it (as a result, one question was restructured due to the ambiguity that seemed to induce in interviewees). These last two procedures were taken in order to fulfill the recommendation proposed by Hill et al. (2005) about consensual qualitative research. All the interviews were conducted by this same person, the first author of this study. Interviews were tape recorded with the permission of the participants, and then transcribed verbatim.

\section{Data analysis}

The participants' narrative was then related to previously defined categories, and, if necessary, new categories were created (these are marked with an asterisk in the table of the all categories presented in Table 2). The general categories were divided into personal and contextual factors, including practice, motivation, personality, micro context, and development conditions and processes. In order to validate this category system, the content grid was firstly tested with $10 \%$ of the total written material, and was subject to minor adjustments when revising the categories (process representing a formative check of reliability). The grid of the preliminary category system was applied by three different researchers, who proceeded with an independent analysis. Then, the intercoder agreement was calculated using Cohen's kappa. The obtained value was .65 and the average percentage of agreement was $93.1 \%$. This was considered an acceptable value, taking into account the general agreement that kappa should vary, for research purposes, between .60 and .70 (Wood, 2007), as well as the complex nature of the data analysis procedure.

The process of data analysis was performed using the qualitative research software NVivo 8.0. It consisted of an open coding that decomposes data into units of analysis. According to its content, a code was assigned to each segment, summarizing its meaning. Subsequently, a systematic comparison between the information waiting to be coded and the information already coded was performed (Schilling, 2006).

\section{Results}

For the quantitative analysis of the categories, we used the method presented by Wao, Dedrick, and Ferron (2010): the computation of theme frequency and theme intensity, followed by its transformation in percentile ranks, which allowed us to obtain a combined measure of consensus in theme endorsement.

Although it is not our intention to perform data analysis in a quantitative basis, we present a descriptive table (Table 2) of categories, in order to provide an overview of the category distributions in terms of its frequency and intensity.

The main findings from the process of data analysis, which are descriptive of each category, were explored, and short excerpts from the interviews were selected based on their representativeness. The quotes are assigned by a code (e.g. PL-F) that links back anonymously to specific sources of data and specific individuals. The data presented here represent the most significant results; this selection resulted from a combination of quantitative and qualitative criteria, which means that in addition 
Table 2. Description of categories in terms of intensity and frequency.

\begin{tabular}{|c|c|c|c|c|c|}
\hline \multirow[b]{2}{*}{ Category } & \multirow[b]{2}{*}{ Subcategory } & \multicolumn{2}{|c|}{ Previous pathway } & \multicolumn{2}{|c|}{$\begin{array}{c}\text { Current } \\
\text { performance }\end{array}$} \\
\hline & & \multicolumn{4}{|c|}{ Intensity Frequency Intensity Frequency } \\
\hline \multicolumn{6}{|l|}{ Contextual factors } \\
\hline \multirow[t]{4}{*}{ Micro context } & Teachers & Moder & Moder & Strong & Strong \\
\hline & Peers and friends & Moder & Moder & Strong & Strong \\
\hline & Family & Moder & Moder & Strong & Strong \\
\hline & Other figures ${ }^{*}$ & Moder & Moder & Moder & Moder \\
\hline \multirow{4}{*}{$\begin{array}{l}\text { Developmental conditions } \\
\text { and processes }\end{array}$} & Learning environments & Moder & Moder & Moder & Strong \\
\hline & $\begin{array}{l}\text { Extra-curricular } \\
\text { activities }\end{array}$ & Moder & Moder & Strong & Strong \\
\hline & $\begin{array}{l}\text { Chance and } \\
\text { opportunities }\end{array}$ & Moder & Moder & Strong & Strong \\
\hline & Previous skills* & Minim & Minim & Moder & Moder \\
\hline \multicolumn{6}{|l|}{ Personal factors } \\
\hline \multirow[t]{20}{*}{ Practice } & Study - quantity ${ }^{*}$ & Moder & Strong & Strong & Strong \\
\hline & $\begin{array}{l}\text { Study - quantity } \\
\text { (negative) }\end{array}$ & Moder & Moder & Moder & Moder \\
\hline & Study - moment ${ }^{*}$ & Moder & Moder & Moder & Moder \\
\hline & Study - quality ${ }^{*}$ & Minim & Minim & Moder & Moder \\
\hline & $\begin{array}{l}\text { Time and activities } \\
\text { management }\end{array}$ & Moder & Minim & Strong & Strong \\
\hline & Organization & Moder & Minim & Strong & Moder \\
\hline & Planning & Minim & Minim & Moder & Moder \\
\hline & $\begin{array}{l}\text { Self-motoring and self- } \\
\text { reflection }\end{array}$ & Minim & Minim & Strong & Strong \\
\hline & Effort and dedication & Moder & Moder & Strong & Strong \\
\hline & Self-discipline & Moder & Moder & Strong & Strong \\
\hline & Deep approach & Moder & Moder & Strong & Strong \\
\hline & $\begin{array}{l}\text { Analysis and problem } \\
\text { solution }\end{array}$ & Minim & Minim & Moder & Moder \\
\hline & $\begin{array}{l}\text { Attention and } \\
\text { concentration }\end{array}$ & Moder & Moder & Moder & Moder \\
\hline & Classes assiduity $_{*}^{*}$ & Minim & Minim & Moder & Moder \\
\hline & Exercise solution & Moder & Moder & Moder & Moder \\
\hline & Reading and research ${ }^{*}$ & Minim & Moder & Moder & Moder \\
\hline & $\begin{array}{l}\text { Preparation and classes } \\
\text { monitoring }\end{array}$ & Minim & Minim & Moder & Moder \\
\hline & Schemas and notes ${ }^{*}$ & Moder & Moder & Moder & Moder \\
\hline & $\begin{array}{l}\text { Performance } \\
\text { improvement }\end{array}$ & Moder & Moder & Moder & Moder \\
\hline & Ask for help & Minim & Minim & Moder & Moder \\
\hline \multirow{5}{*}{ Motivation } & Study engagement & Strong & Strong & Strong & Strong \\
\hline & Performance goals & Moder & Moder & Strong & Strong \\
\hline & Willingness to learn* & Minim & Minim & Moder & Strong \\
\hline & Process goals & Minim & Minim & Moder & Strong \\
\hline & Recognition $^{*}$ & Minim & Minim & Moder & Strong \\
\hline
\end{tabular}


Table 2. (Continued).

\begin{tabular}{llcc}
\hline & & Previous pathway & \multicolumn{1}{c}{$\begin{array}{c}\text { Current } \\
\text { performance }\end{array}$} \\
\cline { 2 - 3 } Category & Subcategory & Intensity Frequency & Intensity Frequency \\
\hline Personality & $\begin{array}{l}\text { Vocational choices and } \\
\text { decisions }\end{array}$ & Strong & Strong \\
$\begin{array}{l}\text { Preferences and } \\
\text { interests }\end{array}$ & Strong & Strong \\
Introversion & Minim & Moder \\
Perfectionism & Strong & Moder \\
Requirement and & Moder & Moder \\
challenge value & Adaptability & Moder & Moder \\
Openness to experience & Moder & Moder \\
Competitiveness & Moder & Moder \\
Determination & Strong & Moder \\
Altruism & Moder & Moder \\
\hline
\end{tabular}

*New categories created as throughout the analysis process.

to the intensity and frequency of the categories, the categories included in the discussion were selected due to their importance to our proposal of understanding the interplay of all factors that characterize excellent engineering students.

The obtained results are presented according to two main vectors - contextual and personal factors (see below in italics) - each composed of a subset of dimensions that were identified as contributing for the response to our research goals.

\section{Contextual factors of excellence}

\section{Micro context (family, teachers, and peers)}

The micro contextual factors lead to the origin of students' pathways, particularly to the role of parents and teachers along their developmental process.

The parents' role is described with respect to the support they provided in a continuum of several forms, and this support seems to be affected by their own academic qualifications. A common kind of support emphasized by all participants concerns logistical and emotional support, school monitoring, as well as the transmission of values related to the importance of effort, persistence, and hard work. In spite of particular family contexts and different school backgrounds, all students demonstrated an ability to adapt to different circumstances, internalizing important characteristics to succeed.

I think I'm lucky to have the parents I have. For example, they always studied a lot, they both have PhDs, my mother is a physician, my father is a teacher, and they always pushed me enough in the sense that you do not have to be the best, but you must do your best. They always incited me, and on summer holidays they always gave me notebooks to exercise and to do fun little things, like Maths (...) that obviously affected the results I have obtained. (PL-F)

(...) my mother is also a bit like me regarding her will to be the best and I probably inherited that from her, and also a bit from my father, in the sense of being stubborn and persistent. I think these are the traits I inherited from them, but not in the sense to teach me something. I've always been autonomous. They do not have sufficient knowledge to teach me. (PM-C) 
The teachers are described as important figures throughout students' academic pathways, namely because of their teaching approach, and by stimulating the development of interests, abilities, and work habits. Participants also felt that their teachers' influence promoted a sense of challenge, and continuous stimulation to progress along their learning.

Mathematics ... I think that it had to do [high performance] with teachers that I had when I was younger, they pushed me harder, and I used to love to solve problems and find a solution. I think it was because of that, teachers motivated me. (PM-A)

The role of teachers was also referred to in relation to the stimulation and incentive they foster to engage in activities beyond traditional academic work. This type of involvement was described as an important opportunity to explore and develop interests and abilities, which came to be important to the quality of learning contents in the future.

(...) I started to learn more advanced things so he [the teacher] would give me more work faster. And I was a bit motivated by that, I decided to do this for myself. This last summer it was he [the teacher] who suggested I study a few things in the meanwhile, in order to advance on afterwards. (PL-B)

Several participants mentioned friends and peers as important figures, because they gave them the opportunity to feel stimulated, or because they shared common interests, which promoted an environment of healthy competition between peers, and motivated a higher level of investment from students. This influence was referred to as critical during elementary school, but also during the current academic phase.

I have a colleague with better grades than me, and this is great, he's an excellent student, and it's not a barrier, it's good, it's good to have very good colleagues, with similar or better performance, to stimulate competitiveness. If I have a question, I won't ask someone who had a lower grade. It's good to have colleagues with high grades ... to exchange information or to ask questions. (PL-C)

(...) my 9th grade colleague, who did the programming contests with me, also had quite an impact on me, because it was also him who dragged me to the field of computing. He had a computer at home and we used to go there to exercise, to put a little robot moving (...) In high school, I think he had quite an influence, he used to do competitions with me and then I went to the Olympiad. (PP-P)

\section{Developmental conditions and processes (extra-curricular activities, learning experiences)}

Parents and teachers also play an active role in the promotion of important conditions associated to students' involvement in several activities, related or unrelated to the subjects studied at the time. Extra-curricular activities, such as sports or music lessons, are described as important opportunities for students to relax and manage stress derived from academic activities. Moreover, such activities are referred to as experiences which promote the development of soft skills, transferable to academic settings (e.g. development of time management habits and emotional regulation strategies). 
In that aspect, sports helped me a lot. When I was a kid, I always was a good student, and at high school there was no big pressure on us, there is much more at university. So I always felt more pressure in sport games than in school tests. (PL-C)

Besides non-academic activities, participants described a set of important learning experiences since early school years, which stimulated their curiosity and provided them with opportunities to explore interests and capacities. These early learning experiences are described by participants as important, since allowing them to build a deeper knowledge base and more effective approaches to learning in the future. Examples of these activities are the participation in programming or mathematics contests, or self-taught projects, such as software development.

(...) I started to play with computers only when I had one at home. So if I did not have a computer at this stage I could not have gone on the $10^{\text {th }}$ grade to the course of computer technology. Then, at the end of $12^{\text {th }}$ grade, the fact that I was selected to go to the Olympiads computing made me gain some practice. (PP-P)

\section{Personal factors of excellence}

\section{Practice (time and activities management, self-monitoring, and self-reflection)}

Concerning participants' practice, we found divergence amongst students in some aspects related to study organization. Some general aspects, such as management of activities and time, or organization of study environment, seem to be more necessary for some students than others, and do not emerge as an essential condition for success for all the participants. Moreover, these divergences between students seem, in some situations, to be related to the personal adaptation to different contextual settings.

At the beginning, in the $1^{\text {st }}$ year, I used to go to every class, but then I realized that there were many lessons that I could replace, as a two-hour class, I could replace for half an hour of home study because I found it easier to get learning material on the internet (...) I retained learning contents in the same way, because in that two-hour lecture, where we were listening to the teacher, I did not learn a lot. So I began to spend that class time at home, studying, and I would only attend class for core lessons. (PP-D)

Another aspect emphasized in the interviews is the participants' capacity to structure and premeditate, which illustrates a tendency to question the purpose of their work (What do I want to understand? What does the teacher want from me?). Students are generally interested in and involved with learning contents; and, while they are able to keep focused on their study, they have also the ability to adapt their study to what is valued and evaluated by their teachers.

I learned the tools I had to use, like a teacher referred to it today "it is the Lego parts with which we can build something. Learn these well ..." We have a goal, to assemble all pieces together, it is what I have always done. I first need to understand that to define the task time. Now, I know how to program, so I do not have to worry about most things in programming, so I just step to the next goal. (PL-E)

Students are able to adapt their strategies to different situations and according to the demands of the context, expressing high abilities to self-monitor learning, in order to ensure that efforts are oriented toward the achievement of the goals they had set. Students also demonstrate a high ability to reflect about the results they achieved, to identify errors and to (re)adapt their strategies to overcome difficulties. 
Thus, the participants demonstrate a high metacognitive awareness, and use control strategies to manage their study.

I think that was the problem, to have too much time and to not have managed well the time with breaks for Christmas and New Year, because obviously I would not study on those dates, I stipulated "stop here". But even so, with these breaks, I did not manage well the time, I'm aware of that. And that was reflected in the results I achieved. (PP-H)

\section{Motivation (study engagement, willingness to learn)}

Students demonstrated different types of motivation, and yet, the different types seem to guide them toward the same direction: learning, and also, high achievement. They report being highly motivated toward learning in general, manifesting passion for knowledge, and ambition to learn more and more; at the same time, they are also motivated toward learning content, expressing enjoyment in solving logical problems or developing projects, often going far beyond what is requested by teachers. These students are generally interested in understanding how things work, show critical thinking, and prefer to create and innovate in what they do. The motivation toward learning seems to become increasingly evident as students progress in their academic pathway: in earlier years, it is identified as an attitude of general curiosity, which is encouraged by parents ("you learn something in everything you do"), becoming more and more focused on specific fields along their academic development.

I've always been very curious, since I was little. And I still am. I was wondering about what electricity was, or how the television worked, or what a stock exchange was, I never realized what a stock exchange was. But at that time ... "How does this work? What is that about finances? How does the banking system work? How does money help the community work?" These were things that fascinated me, and still fascinate. And I love to better understand, more and more, how things work. And that was what helped me liking it [to learn]. (PL-A)

[What makes you engage in your study or work?]

It is essentially to enjoy what I'm studying or what I'm working on (...) If I am studying something just because I will be taking a test, it may be "the later the better". Whereas, if it is something, even when not part of the evaluation, but I do have ... I am curious about it, and I start reading, even with no purpose besides learning, knowing. It is more curiosity. (PM-A)

In some cases, the willingness to learn is an end in itself, for the joy that students feel satisfies their personal curiosity. But in several situations, especially when students reach higher education, learning seems to gain a more conscious and strategic sense; this is a time when students realize that the acquired learning could be useful in the future, putting them at an advantage.

In fact, learning engagement seems to be mainly regulated according to the time students have available and to contextual requirements. This means that, for these students, the enjoyment aroused from what they are doing is important because it makes the learning process easier, more thorough and comprehensive. However, this is not enough to fully understand their practice; for example, students set self-disciplinary strategies to learn materials when the learning process is, for some reason, less enjoyable.

In the case of subjects that did not arouse much interest in me, I study because I know it's important, it's like a school obligation. In any kind of learning there are things that 
are more interesting and others that are less interesting. Or I study because ... I remotely think that it may be important for me in the future. Or just because of the grade, and I study because I have to and so there is no objective reason. (PP-G)

\section{Personality (perfectionism, determination, vocational choices, and preferences and interests)}

Some personality characteristics were identified, namely perfectionism and determination, which seem, together with emotional strategies (such as coping strategies), to make the difference when students deal with obstacles along the way. These characteristics reflect a generally positive attitude of self-confidence when in face of most adverse situations.

The best things I probably ever did were things that I did worse at first. The things in which I had more obstacles, more barriers, and that made me say "give up", at the end I did not give up. (PP-K)

The interests and vocational choices manifested by participants seem to have been fostered since the beginning of their school years, remaining stable until higher education. In general, all participants enjoy learning about sciences and technology, prioritizing logical reasoning and resolution of problems.

I always had some interest in technological stuff, as computers, games (...) After, I always liked Maths. It was always something I ... I found it easier than everything else and I always loved it. Afterwards, the passion for Physics arose at the time of the Olympiads. (PL-B)

Such vocational choices are presented as successful decisions, resulting from a process of active and mature construction, and are interconnected with their general motivation and with the quality of their practice.

\section{Discussion}

The data presented here explore personal and contextual factors that are associated with the development of high achievement among a sample of engineering students.

Before addressing this topic, this study needs firstly to be framed in the context of engineering education in Portugal. Contrary to the majority of their peers, who possibly registered in engineering programs due to "convenience" factors (proximity of residence and more accessible grade to access higher education (CIPES, 2008)) these participants truly wished to pursue engineering. They represent a sample that contrast with traditional and common Portuguese reports of academic failure and dropout, particularly high in engineering courses (GPEARI, 2008), demonstrating how the interest in engineering per se (demonstrated by their vocational choice)is associated with high academic performance.

In this respect, interesting reflections from foreign experiences can be undertaken, namely from Finland (Huvinen, Myller, \& Kairamo, 2010), a country where engineers are very reputed and earn about $20 \%$ more than the average employee having a university degree. In Finland, science and math achievements in secondary education are generally very good, and pupils have to recognize their area of future interest quite early. There is also a shortage of qualified physical science teachers, who might inspire pupils to want to learn more about sciences, which exacerbates the challenge (Schrey-Niemenmaa \& Jones, 2011). This may represent a set of 
conditions that make a difference in the early promotion of talent in engineering education. Such experience not only highlights the importance of development conditions that stimulate students' interests and drive them to their program choice of preference, but also issues a new challenge for universities: to encourage appropriate students to apply for engineering studies, to persuade and encourage them to graduate on time and to have the motivation to follow a career in engineering (Schrey-Niemenmaa \& Jones, 2011).

These findings also consolidate theoretical models of talent development: micro context, as well as developmental conditions and processes, meet the environmental catalysts presented by Gagné $(2000,2004)$ in his DMGT; also, our data converge with the favorable conditions that Ericsson and collaborators (Ericsson et al., 2007; Ericsson, Krampe, \& Tesch-Römer, 1993; Ericsson \& Lehmann, 1996) referred to about early practice. In turn, practice, motivation, and personality fit into the intrapersonal catalysts presented in Gagné's DMGT, which cover behaviors also found in self-regulation literature (Zimmerman, 1998), such as initiative, efficient time management, autonomy, concentration, and effective work habits.

Our data demonstrate that study practice and motivation change as students' progress through the educational system. At earlier stages, curiosity and enjoyment seem to have an essential role in the explanation of engagement in activities (such as mathematics or programming); as students go forward, curiosity and enjoyment become more and more strategic, focused on accomplishing specific intentions and obtaining valued goals (to maintain or obtain high performances). To some extent, our results converge with Bloom's model of talent development (1985), which states that the earlier years are crucial for the development of interests and enjoyment about specific activities, as a result of the encouragement and support received from parents and teachers. In turn, the middle years are characterized by an increasing involvement in domains where students are particularly talented, and by the development of skills, while the later years correspond to the stage of talent refinement, and to a committed involvement and practice in the field where the student is particularly talented.

The description of participants" practice fits the concept of "deliberate practice" mentioned in expert performance approaches (Ericsson \& Lehmann, 1996). However, an interesting aspect can be highlighted from our results, and relates to the enjoyment and sense of challenge that these students seem to feel toward learning: even if able to work and keep focused when facing difficulties and performing apparently unpleasant tasks, enjoyment seems to be implied in such challenge, and pushing activities that matches student's current skills and provide "immediate and informative feedback." In that sense, it represents an important component in understanding how students keep engaged in study practices during the process of questioning contents and solving problems, much more than when the learning task is about finding the (right) solutions.

That aspect is, apparently, in contradiction with a frequent characteristic of deliberate practice activities defined as not inherently enjoyable, and found mainly in some expert performance domains, characterized by continuous isolated practice (e.g. music), as proposed originally by Ericsson and Lehmann (1996), but not found in some practice activities involving more social or group activities (e.g. team sports) (Nordin, Cumming, Vincent, \& McGrory, 2006).

In fact, these students are able to keep focused even when the task is not described as highly enjoyable. Nevertheless, it does not undervalue the importance 
of enjoyment and challenge in academic activities, mainly in earlier stages of development, as it seems strongly related with the way these students engage in study tasks, and with the quality of performance when performing such tasks in engineering courses. In fact, as defined more recently in the expert performance literature, it matches a core attribute of the deliberate practice approach: "individuals seek out new challenges that demand concentration and effort as long as they want to keep improving their performance beyond its current level (...) additional improvement requires increased challenges and engagement in activities selected to improve current performance" (Ericsson et al., 2009, p. 213).

Excellent engineering students demonstrate high levels of autonomy and self-motivation, and seem to be less dependent of teachers' guidelines to define their own strategies and approach to learning situations. This may represent a particularity of the engineering field and curricula, designed to develop critical thinking, problem-solving capacity, and innovation (Felder \& Brent, 2004; Felder, Rugarcia, \& Stice, 2000; Rugarcia, Felder, Woods, \& Stice, 2000). Hence, such abilities seem to require a different approach of deliberate practice from the one proposed by Ericsson as the "individualized training activities especially designed by a coach or teacher to improve specific aspects of an individual's performance through repetition and successive refinement" (Ericsson \& Lehmann, 1996, p. 278).

Another point of analysis of the obtained results focuses on the question: are individuals excellent or do they become excellent? The answer to this question remits us to the initial discussion presented in the literature about acquired versus innate attributes. This study does not allow conclusions about the presence or absence of genetic predispositions. Still, it supports the hypothesis that excellent students act on and react to their contexts, influence, and are influenced by them. Our findings demonstrate how environmental conditions contribute to the development of interests, skills, and competencies, showing that attributes can be acquired over time - when and if in the presence of the appropriate conditions.

Beyond the innate versus acquired discussion, a first and immediate aspect that arises from our data is that a multidimensional and dynamic view about excellence is prevailing. The descriptions made by participants about personal characteristics were largely interrelated with the environmental contexts they were exposed to whether in the past or in the present. People close to these students, specifically, parents and teachers, seem to have influenced the maturation process of working characteristics and personality, shaping the way these students function, either through direct transmission of values, or through the incentive and motivation toward getting involved in learning experiences and several other activities. At the same time, the set of learning experiences and activities in which students were involved appear to have contributed to the promotion of soft skills, such as a sense of responsibility, time, and stress management; to the development of interests and expertise, the participation in contests arousing the interest and involvement in activities of continuous practice was referred by our participants as an important point; and to shape a few personality traits, which make them value work, give their best, and have the will to excel. Such a set of opportunities to explore and experiment in early development stages is likely to define what von Stumm, Hell, and Chamorro-Premuzic (2011) recently called the "hungry mind," referring to intellectual curiosity as the third pillar of academic performance - in other words, as a core characteristic of excellent performers in academic contexts. 
The interrelation between individual development and environmental conditions supports a recent overview by Ackerman (2014) about the nature and nurture determinants of expert performance. Here, he refers to the development of one's interests and motivational profile as a function of early (childhood) experiences of success and failure, along with environmental influences related to the family. Such experiences, in turn, affect the development of self-concept and personal perception of ability. The resulting range of likes and dislikes, along with knowledge and skills are described as the building blocks for future learning. This hypothesis is also supported by our data. Besides early experiences (internal variable) and family influence (external variable), participants' study practices are also described in relation to their contexts; so once again, the symbiosis between internal and external variables becomes clear. Students balance the demands of contextual conditions (e.g. teachers' profile, difficulties experienced during the course, schedules and/or evaluation system) with their own abilities and interests. That relation seems to determine the way they react: the organization of their time, the specific strategies they use, the study skills they develop, and the decisions they must make at each moment. This explains some of the differences found at different times and among different participants, and the difficulty to identify a single working strategy common to all the excellent students interviewed. The ability to monitor contexts, requirements, and academic tasks corresponds to an important particularity in the practice of the participants. Moreover, the relation between personal characteristics and contextual environments assumes a mutual direction: while individuals present an active role along their own pathway and over their own contexts, these also tend to react to individuals' needs and responses.

A second insight deriving from this study is that there seem to be different possible pathways or different sets of environmental conditions to achieve excellence. From the diversity of family backgrounds, one common and general aspect seems to emerge: the transmission of important values and attitudes toward work, and the importance to be endeavored and strive to obtain long-term goals. At the same time, students' motivation and task involvement seem to evolve and change as they move forward along their academic education. In early academic years, pleasure and enjoyment seem to play an important role in activities related to practice; however, as students evolve in learning, other skills related to self-regulation and self-discipline seem to become important. And at the moment of university entrance, the enjoyment resulting from learning is described as an important aspect, but it does not appear to be the only one to understand students' achievement. At this stage, long-term motivations, such as the ambition to become an excellent professional, play an important role, guiding study behaviors. In sum, if the beginning of the educational pathway may be characterized by the mere pleasure of learning, apparently lacking defined goals, in more advanced stages of learning (typical of higher education), practice activities seem to be targeted by much more specific goals, overcoming the enjoyment provided by practice.

Students are reactive and adaptive, working continuously to achieve the goal to excel, and planning their current and future academic courses. In the light of this perspective, academic excellence is presented as a process under continuous development, which starts during childhood, in the family context and school environment, and seems to be constantly nurtured by individuals in interaction with their contexts. This represents our third insight, which is closely related to the previous one. 


\section{Concluding remarks}

The present study represents a contribution in the attempt to create an integrative mapping of the different potential forces and strengths associated to academic excellence. In short, three main contributions from our study can be highlighted, concerning the conceptualization and understanding of excellence in academic contexts: (i) a multidimensional and dynamic view about the concept must be used; (ii) there is a variety of possible pathways and environmental conditions to achieve excellence; and (iii) excellence should be understood as a process undergoing continuous development, which thrives in accordance with family context and school environment, as well as being continuously nurtured by environmental conditions. These findings confirm our previous hypothesis about a mutual interdependence between personal and contextual factors, corresponding to a developmental and systemic process, as excellence seems to be the product of more than just single individual characteristics. Rather, it appears to result from multiple individual and contextual factors, operating from earlier stages. This strengthens the recent theory presented by Ziegler and Phillipson (2012), by corroborating with empirical data how contextual and personal factors can interact for the construction of a route of excellence. It seems to us that excellence cannot be conceptualized as fully completed at a specific development stage, but rather as a process on continuous nurturance and evolution. According to this perspective, becoming excellent seems a more appropriate term than being excellent, which would remit us to a dichotomous state of to be or not to be excellent. Excellence is presented here as a developmental and systemic process, in a continuous mutual interdependence between personal and contextual factors. This central idea of "be(com)ing excellent" also underlines and supports recent views of giftedness as "developing expertise," as suggested by Sternberg (2001), which challenge the old assumption that being "gifted" or "excellent" is "actually something real and permanent" (Pfeiffer, 2012). For this same reason, it does not seem relevant to look for "a formula of excellence," as if excellence would represent an ended and confined product reduced to a sum of isolated factors.

\section{Limitations and future directions}

The present study provides important data to understand how different personal and contextual factors interact with each other in the development of excellence. Nevertheless, there are some contextual limitations that need to be considered. In order to increase the significance of our findings, it would be interesting to combine multiple points of view about this research topic, using data triangulation, with interviews to parents and teachers, besides the interviews we conducted to students. Moreover, it is also important to emphasize the particularities of engineering courses in Portugal (with a general low demand to access, high failure, and high dropout rates) that make our participants' characteristics distinctive. Quite different results should be found in a country like Korea, where students are at the top of the ranks of mathematics in PISA reports (OCDE, 2014), and where engineering is a line of work that is culturally valued.

Finally, the findings presented here reinforce learning as a process that occurs in a social context (Bandura, 1986), and that should be integrated and considered in future empirical research. Further studies concerning these issues are needed. One important next step in future research would be to consider additional comparative 
samples in terms of level of achievement. Such a contribution would allow a clearer understanding of the impact of different environmental conditions and the influence of students' profile on excellent achievement.

\section{References}

Ackerman, P. L. (2014). Nonsense, common sense, and science of expert performance: Talent and individual differences. Intelligence, 45, 6-17.

Araújo, L. S., Cruz, J. F., \& Almeida, L. (2011). A entrevista no estudo da excelência: Uma proposta [The interview in the study of excellence: A proposal]. Psychologica, 52, 253280.

Bandura, A. (1986). Social foundations of thought and action: A social cognitive theory. Englewood Cliffs, NJ: Prentice-Hall.

Bloom, B. S. (1985). Developing talent in young people. New York, NY: Ballantine.

Butler, D. L. (2002). Qualitative approaches to investigating self-regulated learning: Contributions and challenges. Educational Psychologist, 37, 59-63.

CIPES. (2008). A rede pública de ensino superior: Um olhar sobre o acesso [The public higher education: An overview on the access]. Porto: Cipes.

Ericsson, K. A., Krampe, R. T., \& Tesch-Römer, C. (1993). The role of deliberate practice in the acquisition of expert performance. Psychological Review, 100, 363-406.

Ericsson, K. A., \& Lehmann, A. C. (1996). Expert and exceptional performance: Evidence of maximal adaptation to task constraints. Annual Review of Psychology, 47, 273-305.

Ericsson, K. A., Nandagopal, K., \& Roring, R. W. (2009). Toward a science of exceptional achievement. Annals of the New York Academy of Sciences, 1172, 199-217.

Ericsson, K. A., Roring, R. W., \& Nandagopal, K. (2007). Giftedness and evidence for reproducibly superior performance: An account based on the expert performance framework. High Ability Studies, 18, 3-56.

Ericsson, K. A., \& Smith, J. (1991). Toward a general theory of expertise: Prospects and limits. New York, NY: Cambridge University Press.

Felder, R. M., \& Brent, R. (2004). The intellectual development of science and engineering students 2. Teaching to promote growth. Engineering, 93, 279-291.

Felder, R. M., Rugarcia, A., \& Stice, J. E. (2000). The future of engineering education II. Teaching methods that work. Engineering Education, 34, 108-117.

Gagné, F. (2000). A differentiated model of giftedness and talent (DMGT). Retrieved from http://www.curriculumsupport.education.nsw.gov.au/policies/gats/assets/pdf/poldmg

Gagné, F. (2004). Transforming gifts into talents: The DMGT as a developmental theory. High Ability Studies, 15, 119-147.

GPEARI. (2008). Índice de sucesso escolar no ensino superior (cursos de formação inicial) 2005-2006 [Success index at higher education (Initial training courses) 2005-2006]. Lisboa: GPEARI/MCTES.

Heller, K. A. (2004). Identification of gifted and talented students. Psychological Science, 46, $302-323$.

Hill, C. E., Knox, S., Thompson, B. J., Williams, E. N., Hess, S. A., \& Ladany, N. (2005). Consensual qualitative research: An update. Journal of Counseling Psychology, 52, 196205.

Howe, M. J. A., Davidson, J. W., \& Sloboda, J. A. (1998). Innate talents: Reality or myth? Behavioral and Brain Sciences, 399-407.

Huvinen, O., Myller, E., \& Kairamo, A.-K. (2010, September 19-22). Networking opportunities and challenges in developing teaching and counselling. In EE', Proceedings of IGIPSEFI conference (pp. 43-44 and CD p. 1254), Trnava.

Lee, K. H., \& Sriraman, B. (2012). Gifted girls and nonmathematical aspirations: A longitudinal case study of two gifted Korean girls. Gifted Child Quarterly, 56, 3-14.

Lubinski, D., \& Benbow, C. P. (2006). Study of mathematically precocious youth after 35 years: Uncovering antecedents for the development of math-science expertise. Perspectives on Psychological Science, 1, 316-345.

Lubinski, D., Benbow, C. P., Webb, R. M., \& Bleske-Rechek, A. (2006). Tracking exceptional human capital over two decades. Psychological Science, 17, 194-199. 
Lubinski, D., Webb, R. M., Morelock, M. J., \& Benbow, C. P. (2001). Top 1 in 10,000: A 10-year follow-up of the profoundly gifted. Journal of Applied Psychology, 86, 718-729.

Nandagopal, K., \& Ericsson, K. A. (2012). An expert performance approach to the study of individual differences in self-regulated learning activities in upper-level college students. Learning and Individual Differences, 22, 597-609.

Nordin, S. M., Cumming, J., Vincent, J., \& McGrory, S. (2006). Mental practice or spontaneous play? Examining which types of imagery constitute deliberate practice in sport. Journal of Applied Sport Psychology, 18, 345-362.

OCDE. (2014). PISA 2012 results: What students know and can do-Student performance in mathematics reading and science (Vol. 1, Revised ed.). Pisa: OECD.

Pfeiffer, S. I. (2012). Lessons learned from working with high-ability students. Gifted Education International, 29, 86-97.

Renzulli, J. S. (1986). The three-ring conception of giftedness: A developmental model for creative productivity. In R. J. Sternberg \& J. E. Davidson (Eds.), Conceptions of giftedness (pp. 53-92). New York, NY: Cambridge University Press.

Rugarcia, A., Felder, R. M., Woods, D. R., \& Stice, J. (2000). The future of engineering education I. A vision for a new century. Chemical Engineering Education, 34, 16-25.

Schilling, J. (2006). On the pragmatics of qualitative assessment. European Journal of Psychological Assessment, 22, 28-37.

Schrey-Niemenmaa, K., \& Jones, M. E. (2011). Attractiveness in engineering education: Is all as it seems? In Proceedings of SEFI annual conference, Lisbon.

Sternberg, R. J. (1998). Metacognition, abilities, and developing expertise: What makes an expert student? Instructional Science, 26, 127-140.

Sternberg, R. J. (2001). Giftedness as developing expertise: A theory of the interface between high abilities and achieved excellence. High Ability Studies, 12, 159-179.

Teddlie, C., \& Tashakkori, A. (2009). Foundations of mixed methods research: Integrating quantitative and qualitative approaches in the social and behavioral sciences. Los Angeles, CA: Sage.

Vasconcelos, R. M., Almeida, L., \& Monteiro, S. (2006). Academic profile of first-year engineering students. In P. Andersson \& C. Borri (Eds.), SEFI - 34th annual conference: Engineering education and active students (pp. 59-65). Uppsala: Uppsala University, Faculty of Science and Technology.

von Stumm, S., Hell, B., \& Chamorro-Premuzic, T. (2011). The hungry mind: Intellectual curiosity is the third pillar of academic performance. Perspectives on Psychological Science, 6, 574-588.

Wao, H. O., Dedrick, R. F., \& Ferron, J. M. (2010). Quantitizing text: Using theme frequency and theme intensity to describe factors influencing time-to-doctorate. Quality \& Quantity, 45, 923-934.

Whittemore, R., Chase, S. K., \& Mandle, C. L. (2001). Validity in qualitative research. Qualitative Health Research, 11, 522-537.

Wood, J. M. (2007). Understanding and computing Cohen's kappa: A tutorial. WebPsychEmpiricist. Retrieved from http://wpe.info/vault/wood07/Wood07.pdf

Yin, R. K. (1994). Case study research: Design and methods (2nd ed.). Thousand Oaks, CA: Sage.

Ziegler, A., \& Heller, K. A. (2000). Conceptions of giftedness from a meta-theoretical perspective. In K. A. Heller, F. J. Mönks, R. J. Sternberg, \& R. F. Subtonik (Eds.), International handbook of giftedness and talent (pp. 3-21). New York, NY: Elsevier.

Ziegler, A., \& Phillipson, S. N. (2012). Towards a systemic theory of gifted education. High Ability Studies, 23, 3-30.

Zimmerman, B. J. (1998). Academic studing and the development of personal skill: A selfregulatory perspective. Educational Psychologist, 33, 73-86.

Zimmerman, B. J. (2006). Development and adaptation of expertise: The role of self-regulatory processes and beliefs. In K. A. Ericsson, N. Charness, P. J. Feltovich, \& R. R. Hoffman (Eds.), The Cambridge handbook of expertise and expert performance (pp. 705722). Cambridge: Cambridge University Press.

Zimmerman, B. J. (2008). Investigating self-regulation and motivation: Historical background, methodological developments, and future prospects. American Educational Research Journal, 45, 166-183. 